Property modelling

\title{
Nanoindentation creep of nonlinear viscoelastic polypropylene
}

\author{
Guangjian Peng a , Yi Ma ${ }^{\mathrm{a}}$, Yihui Feng ${ }^{\mathrm{b}}$, Yong Huan ${ }^{\mathrm{b}}$, Chunjie Qin ${ }^{\mathrm{a}}$, \\ Taihua Zhang a," \\ a College of Mechanical Engineering, Zhejiang University of Technology, Hangzhou 310014, China \\ b State Key Laboratory of Nonlinear Mechanics (LNM), Institute of Mechanics, Chinese Academy of Sciences, Beijing 100190, China
}

\section{A R T I C L E I N F O}

\section{Article history:}

Received 9 January 2015

Accepted 15 February 2015

Available online 21 February 2015

\section{Keywords:}

Nonlinear viscoelasticity

Creep compliance

Nanoindentation

Polypropylene

\begin{abstract}
A B S T R A C T
Uniaxial tensile creep tests at various applied stresses were carried out to demonstrate that PP is nonlinear viscoelastic. A novel phenomenological model consisting of springs, dashpots, stress-locks and sliders was proposed to describe the nonlinear viscoelasticity. Indentation creep tests at different applied load levels were also performed on nonlinear viscoelastic PP. It was found that the shear creep compliance varies with the applied load level when the applied load is less than $5 \mathrm{mN}$, which means the indentation creep behavior was nonlinear. To find the real reason for the nonlinearity in indentation creep tests, the elastic modulus at various indentation depths was measured using continuous stiffness measurements (CSM). By analyzing the variation of elastic modulus with indentation depth, the nonlinearity of indentation creep behavior was proved to be caused by the non-uniform properties in the surface of the specimen rather than nonlinear viscoelasticity.
\end{abstract}

(C) 2015 Elsevier Ltd. All rights reserved.

\section{Introduction}

Since polymeric materials and polymer-matrix composites are widely used as load-carrying components in many structural applications, their mechanical properties, which are very important for product design, should be characterized by reliable approaches. With the development of micromachining processes, polymeric components and structures become smaller and smaller. The conventional testing techniques face great challenge when applied to such products due to the difficulty of specimen preparation. Nanoindentation, where tests are conducted in a small region (typically $1 \mu \mathrm{m}-10 \mu \mathrm{m}$ in diameter) on the surface of actual components with little specimen preparation, is an efficient and convenient tool for probing the

\footnotetext{
* Corresponding author. No. 18, Chaowang Road, Hangzhou 310014, China. Tel.: +86571 88320762 .

E-mail address: zhangth@zjut.edu.cn (T. Zhang).
}

local mechanical properties of small volumes of materials such as polymeric thin films deposited on substrates, and small structures such as Micro-Electro-MechanicalSystems (MEMS).

A large body of literature has described the analysis of the nanoindentation response for polymers whose behavior is typically time-dependent [1-10]. In the literature, the majority of the researchers assumed that polymers are linear viscoelastic, and the shear creep compliance is usually used to characterize the timedependent response [1-7]. The shear creep compliance $J(t)$ is defined as the change in strain as a function of time under instantaneous application of a constant stress, or

$J(t)=2(1+\nu) \frac{\varepsilon(t)}{\sigma_{0}}$

where $\nu$ is the time-independent Poisson's ratio of the sample. The shear creep compliance can be measured directly via conventional tension or compression creep 
tests [11]. Based on the viscoelastic contact solution derived by Lee and Radok [12], Hunter [13], Graham [14] and Ting [15], researchers have increasingly proposed instrumented (conical and spherical) indentation methods to determine the shear creep compliance [1-9]. For the case of a conical indenter indenting the sample with an instantaneously applied and constant load, $F_{0}$, the shear creep compliance can be calculated by

$J(t)=\frac{4 \tan \alpha}{\pi(1-\nu) F_{0}} h^{2}(t)$

where $\alpha$ is the included half-angle of the conical indenter; $h(t)$ is the indentation depth. In the linear viscoelastic regime, the shear creep compliance is independent of test method and conditions. To validate this, tensile creep tests at various applied stresses, and indentation creep tests at various applied loads were carried out on an ideal linear viscoelastic solid in the commercial finite element program ABAQUS. The computational results shown in Fig. 1 illustrate that the shear creep compliance is indeed invariant with applied stress in tensile creep tests and applied load in indentation creep tests.

For nonlinear viscoelastic solids, however, the shear creep compliance varies with the applied stress. Jazouli et al. [16] studied the nonlinear creep behavior of polycarbonate (PC) via uniaxial tensile creep tests at different stress levels and found that the creep compliance increases with the applied stress. Tweedie et al. [9] observed that the assumption of linear viscoelasticity breaks down for several polymers (including polycarbonate and polypropylene) when creep compliance is measured via conical indentation. Oyen [17] discussed the geometrical nonlinearity and material nonlinearity for indentation of nonlinear viscoelastic solids. These researchers did great work but did not reveal the real reason for the nonlinearity in indentation creep tests.

In the present work, a phenomenological model composed of springs, dashpots, stress-locks and sliders is proposed to describe the stress-dependent shear creep compliance. Both uniaxial tensile creep tests at three different stress levels and indentation creep tests at seven different load levels were carried out on polypropylene (PP) in order to find the real reason for the nonlinearity in conical indentation creep tests.

\section{Phenomenological model}

For nonlinear viscoelastic polymers, the creep compliance increases with the applied stress. Generally, four main types of deformation, i.e. elastic, plastic, viscoelastic and viscoplastic, exist during indentation. To describe these features and the nonlinear viscoelasticity, a phenomenological model shown in Fig. 2 was proposed. In this model, a novel element called "stress-lock" was adopted. The property of stress-lock is characterized by a critical stress, $\sigma^{*}$, which can be regarded as the stress-key to the stress-lock. When the applied stress is equal to or less than $\sigma^{*}$, the stress-lock element remains locked and no deformation is allowed; when the applied stress is greater than $\sigma^{*}$, the stress-lock element is unlocked and deformation occurs
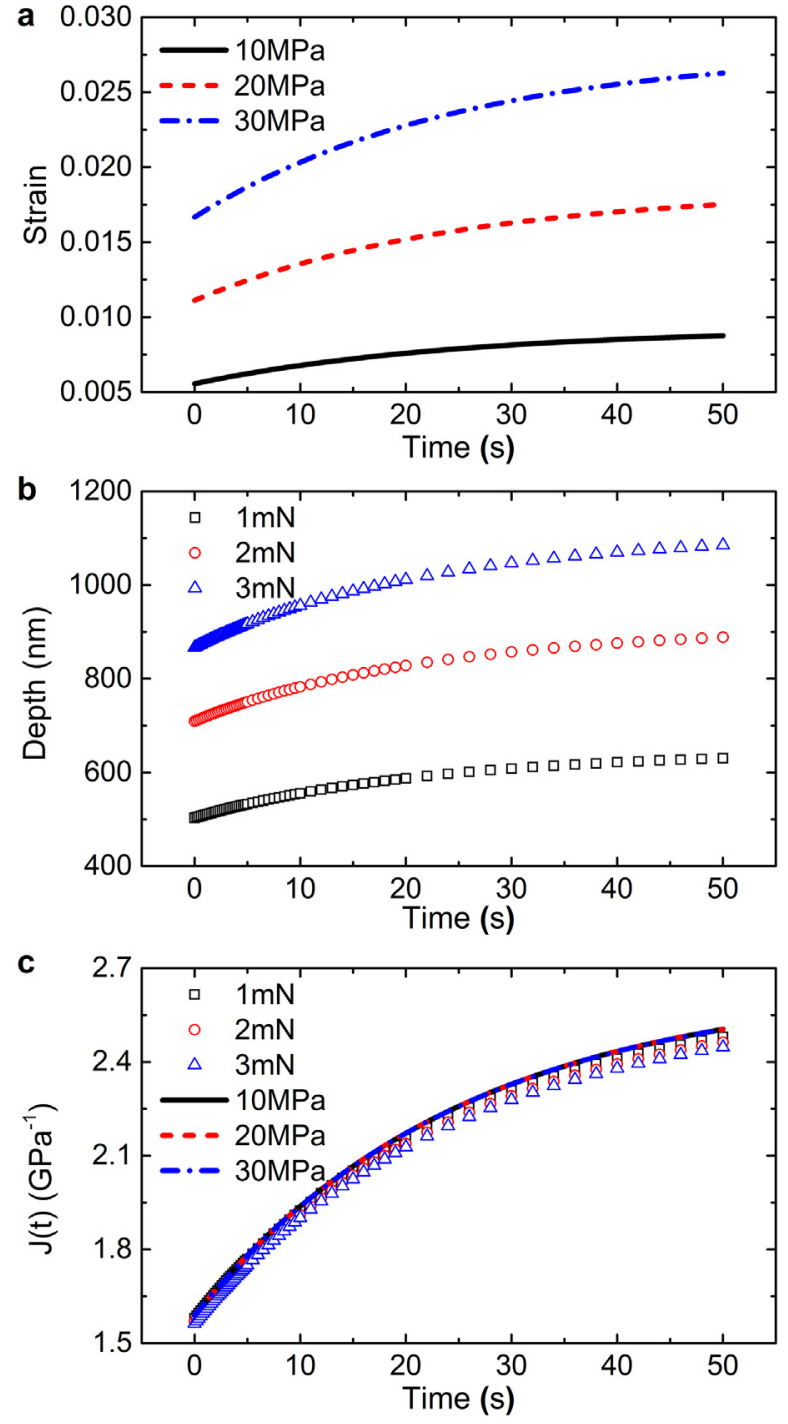

Fig. 1. Linear creep behaviors for an ideal linear viscoelastic material that constructed in ABAQUS. (a) The strain-time curves measured by uniaxial tensile creep tests at applied stress of $10 \mathrm{MPa}, 20 \mathrm{MPa}$ and $30 \mathrm{MPa}$ deviate from each other. (b) The depth-time curves for indentation creep tests at applied load of $1 \mathrm{mN}, 2 \mathrm{mN}$ and $3 \mathrm{mN}$ also deviate from each other. (c) The shear creep compliance determined by uniaxial tensile creep tests and indentation creep tests coincides well with each other.

freely. Thus, the locked Voigt-Kevin unit (a stress-lock, a spring and a dashpot in parallel) in the phenomenological model only works when the applied stress is greater than the corresponding stress-key, $\sigma_{i}^{*}$. As shown in Fig. 2, the Maxwell unit (a spring in series with a dashpot) is able to describe elastic deformation and stress relaxation; the Voigt-Kevin unit (a spring and a dashpot in parallel) is able to describe linear viscoelastic deformation; the viscoplastic unit (a slider and a dashpot in parallel) is able to describe viscoplastic deformation (the strain hardening after yielding is neglected here); the locked Voigt-Kevin units in series are able to describe nonlinear viscoelastic deformation because they can be equivalent to different viscoelastic 


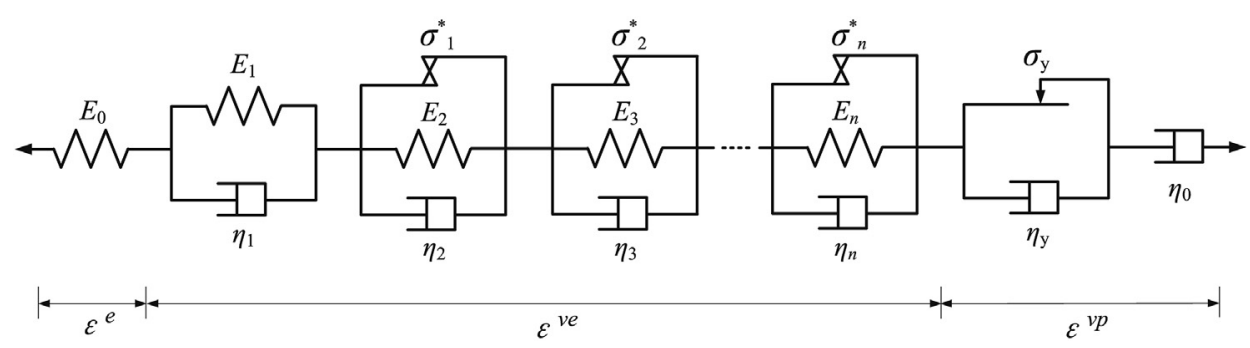

Fig. 2. Phenomenological model to describe the nonlinear viscoelasticity. $E_{0}, E_{1}, E_{2}, E_{3}, \ldots, E_{n}$ are the elastic moduli of the spring elements; $\eta_{0}, \eta_{1}, \eta_{2}, \eta_{3}, \ldots, \eta_{n}$ and $\eta_{\mathrm{y}}$ are the viscosity coefficients of the dashpot elements; $\sigma_{1}^{*}, \sigma_{2}^{*}, \ldots, \sigma_{n}^{*}$ are the stress-keys for the stress-lock elements; and $\sigma_{\mathrm{y}}$ is the yield strength of the slider.

models as the applied stress increases. The more locked Voigt-Kevin units that are used, the more are the equivalent viscoelastic models as the applied stress increases, and the better the phenomenological model describes the nonlinear viscoelasticity.

For a Maxwell unit in series with one or more VoigtKevin units, the shear creep compliance function is [18].

$J(t)=J_{0}+\sum J_{i}\left[1-\exp \left(-t / \tau_{i}\right)\right]+t / \eta_{0}$

where $J_{0}$ and $J_{i}$ are compliance constants; $\tau_{i}$ are the retardation time constants that related to the compliance $J_{i}$ of the spring and the viscosity $\eta_{i}$ of the dashpot in the $i$ th Voigt-Kevin unit as $\tau_{i}=\eta_{i} J_{i} ; \eta_{0}$ is the viscosity of the dashpot in Maxwell unit. The compliances $J_{i}$ can be related to elastic moduli $E_{i}$ and Poisson's ratio $\nu$ by

$J_{i}=\frac{2\left(1+\nu^{2}\right)}{E_{i}}$

If the viscoplastic unit is activated, the shear creep compliance function can be rewritten as

$J(t)=J_{0}+\sum J_{i}\left[1-\exp \left(-t / \tau_{i}\right)\right]+t / \eta_{\mathrm{y}}+t / \eta_{0}$

where $\eta_{\mathrm{y}}$ is the viscosity of the dashpot in the viscoplastic unit. It only works after material yielding.

\section{Experiments}

\subsection{Specimens}

Uniaxial tensile tests and indentation tests were carried out on PP (Anheda Plastic Products Co., Ltd., Suzhou, China). A four-millimeter-thick PP plate was processed into dumbbell-shaped specimens according to ISO 527-2 [19] for uniaxial tensile tests, and was cut into small square specimens measuring $20 \mathrm{~mm} \times 20 \mathrm{~mm}$ for indentation tests. All specimens were annealed at $105^{\circ} \mathrm{C}$ for 2.5 hours in air to relieve the residual stress caused by mechanical processing.

\subsection{Uniaxial tensile tests}

An Instron ElectroPuls E10000 material testing system was used to perform the uniaxial tensile creep tests at room temperature $\left(21^{\circ} \mathrm{C}\right)$. The creep tests were carried out at three different stress levels. Since the yield strength of PP is about $35 \mathrm{MPa}$, the applied stresses were set to $10 \mathrm{MPa}$,
$15 \mathrm{MPa}$ and $20 \mathrm{MPa}$ to avoid plastic deformation. An instantaneous stress was applied to the specimen in $1 \mathrm{~s}$ and then held constant for $500 \mathrm{~s}$. The uniaxial tensile creep test at each stress level was repeated 3 times.

\subsection{Indentation tests}

The indentation tests were conducted at the room temperature $\left(21^{\circ} \mathrm{C}\right)$ using a Agilent Nano Indenter G200 system with a Berkovich indenter, which can be modeled as an equivalent cone with an included half-angle of $70.3^{\circ}$. The indentation creep tests were performed using a quasistep-hold loading profile with seven different load levels (i.e. $0.5 \mathrm{mN}, 1 \mathrm{mN}, 2 \mathrm{mN}, 3 \mathrm{mN}, 5 \mathrm{mN}, 7.5 \mathrm{mN}$ and $10 \mathrm{mN}$ ). For each applied load level, the load was increased quickly to the maximum in $1 \mathrm{~s}$ and held constant for $500 \mathrm{~s}$. To study the resultant variation of elastic modulus with the indentation depth using continuous stiffness measurements (CSM) [20], constant strain rate $\left(\dot{h} / h=0.05 \mathrm{~s}^{-1}\right)$ indentation tests were performed by applying a small oscillation to the force signal at a frequency of $45 \mathrm{~Hz}$. During indentation tests, the drift rate due to temperature variation was within $\pm 0.02 \mathrm{~nm} / \mathrm{s}$. The possibly maximum thermal drift was $\pm 10 \mathrm{~nm}$ for a test that lasts $500 \mathrm{~s}$, which is much smaller than the indentation depth (about $0.6 \mu \mathrm{m}-2 \mu \mathrm{m}$ ). Each indentation test was repeated 5 times.

\section{Results and discussion}

\subsection{Uniaxial tensile results}

The shear creep compliance of PP determined by uniaxial tensile creep tests at applied stress of $10 \mathrm{MPa}, 15 \mathrm{MPa}$ and $20 \mathrm{MPa}$ is plotted in Fig. 3. It is clear that the shear creep compliance increases with the applied stress. This demonstrates that PP is nonlinear viscoelastic.

The nonlinearity of viscoelasticity can be described using the phenomenological model, as shown in Fig. 2. To describe the different creep behavior at three different applied stresses, at least two locked Voigt-Kevin units should be included in the phenomenological model. For simplicity, only two locked Voigt-Kevin units were adopted here in the PP-model (see Fig. 4). The stress-key, $\sigma_{1}^{*}$, for the stress-lock in the first locked Voigt-Kevin unit takes a value of 14.9 MPa, and the stress-key, $\sigma_{2}^{*}$, for the second stresslock takes a value of $19.9 \mathrm{MPa}$. Since all applied stresses are less than the yield strength ( $35 \mathrm{MPa}$ ), the viscoplastic 


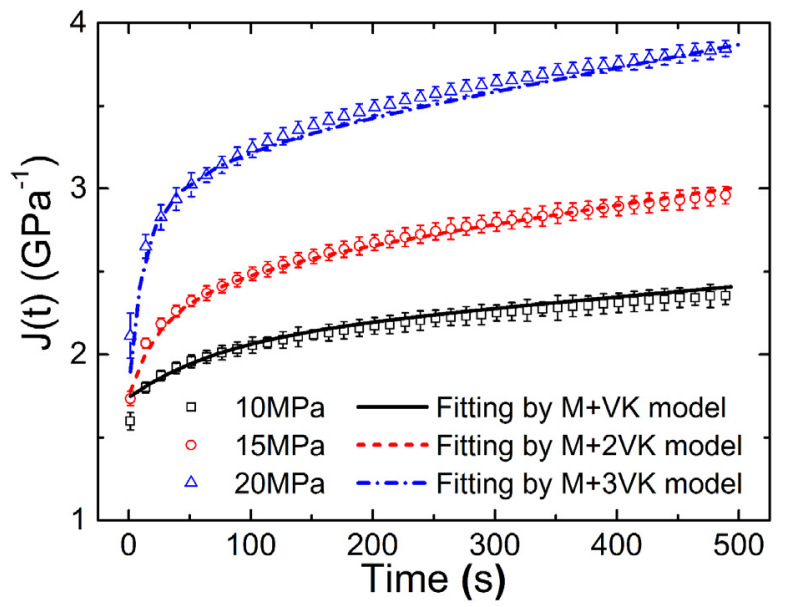

Fig. 3. Shear creep compliance determined by uniaxial tensile tests at applied stress of $10 \mathrm{MPa}, 15 \mathrm{MPa}$ and $20 \mathrm{MPa}$, and was approximated by $\mathrm{M}+\mathrm{VK}$ model, $\mathrm{M}+2 \mathrm{VK}$ model and $\mathrm{M}+3 \mathrm{VK}$ model, respectively.

unit does not work. The PP-model reduces to a Burgers model (i.e. one Maxwell unit in series with one Voigt-Kevin unit, $\mathrm{M}+\mathrm{VK}$ ) for the applied stress of $10 \mathrm{MPa}$. For the applied stress of $15 \mathrm{MPa}$, the first stress-lock is unlocked, and the PP-model is equivalent to a Maxwell unit in series with two Voigt-Kevin units, $M+2 V K$. Similarly, the second stress-lock is unlocked for the applied stress of $20 \mathrm{MPa}$, and the PP-model reduces to a Maxwell unit in series with three Voigt-Kevin units, M+3VK. As a consequence, the shear creep compliance obtained at applied stress of $10 \mathrm{MPa}$, $15 \mathrm{MPa}$ and $20 \mathrm{MPa}$ was approximated by $\mathrm{M}+\mathrm{VK}, \mathrm{M}+2 \mathrm{VK}$ and $\mathrm{M}+3 \mathrm{VK}$, expressed by Eq. (3), respectively. Fig. 3 shows that the three models generated by the PP-model can approximately describe the different shear creep compliance at various applied stresses. The values of the parameters for elements in PP-model were listed in Table 1.

\subsection{Indentation results}

Fig. 5 shows the typical load-depth curves for indentation creep tests on PP at seven different load levels, i.e.

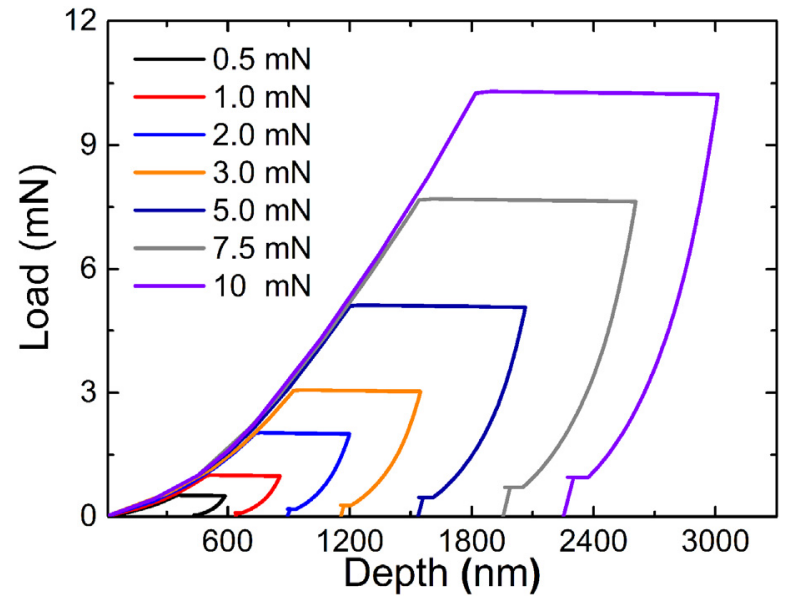

Fig. 5. Typical indentation load-depth curves for conical indentation creep tests on PP at seven different applied loads.

$0.5 \mathrm{mN}, 1 \mathrm{mN}, 2 \mathrm{mN}, 3 \mathrm{mN}, 5 \mathrm{mN}, 7.5 \mathrm{mN}$ and $10 \mathrm{mN}$. It can be deduced from Fig. 5 that the indentation depth range during holding segment is about $350 \mathrm{~nm}-600 \mathrm{~nm}$ for an applied load of $0.5 \mathrm{mN}$, about $550 \mathrm{~nm}-850 \mathrm{~nm}$ for an applied load of $1 \mathrm{mN}$, about $800 \mathrm{~nm}-1200 \mathrm{~nm}$ for an applied load of $2 \mathrm{mN}$, about $950 \mathrm{~nm}-1550 \mathrm{~nm}$ for an applied load of $3 \mathrm{mN}$, about $1250 \mathrm{~nm}-2050 \mathrm{~nm}$ for an applied load of $5 \mathrm{mN}$, about $1550 \mathrm{~nm}-2550 \mathrm{~nm}$ for an applied load of $7.5 \mathrm{mN}$ and about $1800 \mathrm{~nm}-3000 \mathrm{~nm}$ for an applied load of $10 \mathrm{mN}$. The revised step-hold method presented in our previous work [21] was used to determine the shear creep compliance. The mean value of shear creep compliance determined by indentation creep tests at seven different load levels was plotted in Fig. 6. It is evident that the shear creep compliance varies with the applied load when the load is less than $5 \mathrm{mN}$, and comes to a steady state when the applied load is equal to or greater than $5 \mathrm{mN}$. This means the nonlinear indentation creep behavior may not be caused by nonlinear viscoelasticity but by size effects.

To find the real reason for the nonlinearity in indentation creep tests, the elastic moduli at various indentation

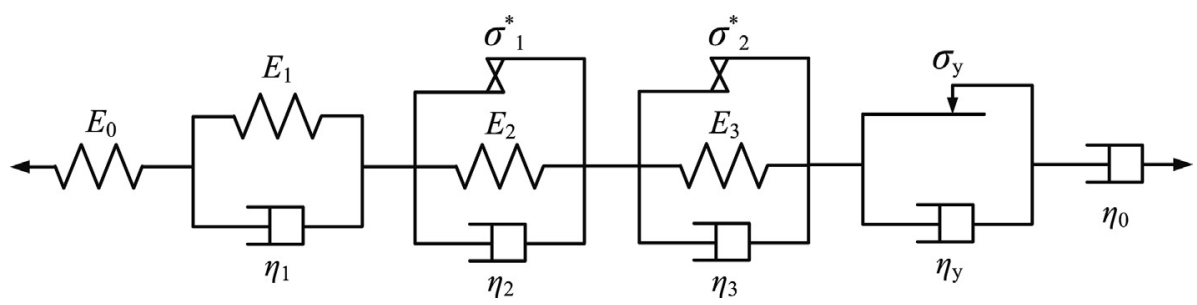

Fig. 4. PP-model to describe the creep properties of nonlinear viscoelastic PP.

Table 1

Parameters for the elements in PP-model and Poisson's ratio takes value of 0.43

\begin{tabular}{|c|c|c|c|c|c|c|c|c|c|c|c|}
\hline$E_{0}(\mathrm{GPa})$ & $E_{1}(\mathrm{GPa})$ & $\eta_{1}(\mathrm{GPa} \cdot \mathrm{s})$ & $\sigma_{1}^{*}(\mathrm{MPa})$ & $E_{2}(\mathrm{GPa})$ & $\eta_{2}(\mathrm{GPa} \cdot \mathrm{s})$ & $\sigma_{2}^{*}(\mathrm{MPa})$ & $E_{3}(\mathrm{GPa})$ & $\eta_{3}(\mathrm{GPa} \cdot \mathrm{s})$ & $\sigma_{\mathrm{y}}(\mathrm{MPa})$ & $\eta_{\mathrm{y}}(\mathrm{GPa} \cdot \mathrm{s})$ & $\eta_{0}(\mathrm{GPa} \cdot \mathrm{s})$ \\
\hline 1.36 & 6.77 & 215.29 & 14.90 & 6.40 & 51.51 & 19.90 & 3.34 & 11.99 & 35.0 & $\mathrm{~N} / \mathrm{A}$ & 906.98 \\
\hline
\end{tabular}




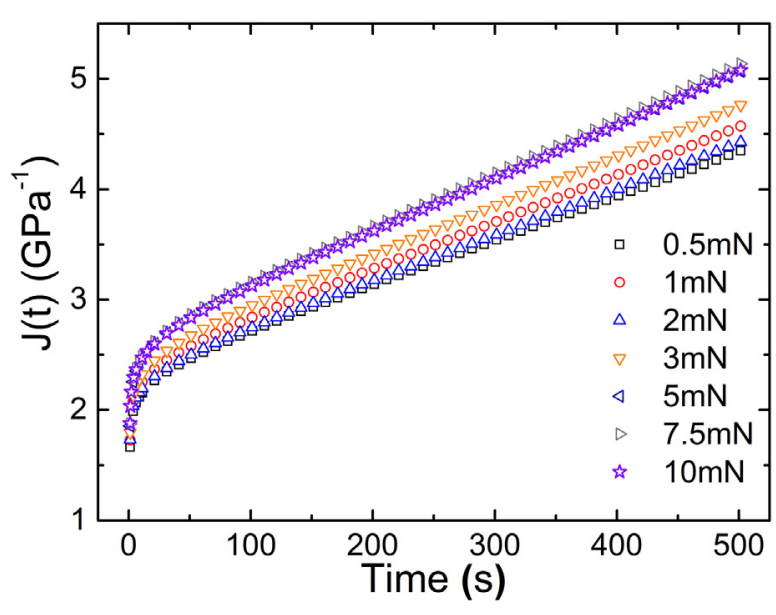

Fig. 6. Shear creep compliance for PP determined by conical indentation creep tests at seven different applied loads.

depths, measured by continuous stiffness measurements (CSM) [20], were plotted in Fig. 7. It is clear that the elastic modulus varies with the indentation depth at shallow depths, and tends to being stable after the indentation depth increases to $1200 \mathrm{~nm}$. This demonstrates that the properties in the surface of the specimen are not uniform. As we know, higher elastic modulus leads to lower creep compliance. Since the shear creep compliance was determined using the depth-time data during the holding segment, the elastic modulus in the indentation depth range during holding would influence the shear creep compliance. Fig. 7 also shows the indentation depth ranges during holding segment for different applied loads. It can be inferred from Fig. 7 that the shear creep compliance determined by indentation creep tests at applied load of $0.5 \mathrm{mN}$ will be the smallest because the average elastic modulus calculated from $350 \mathrm{~nm}$ to $600 \mathrm{~nm}$ is the largest. The shear creep compliance determined by indentation

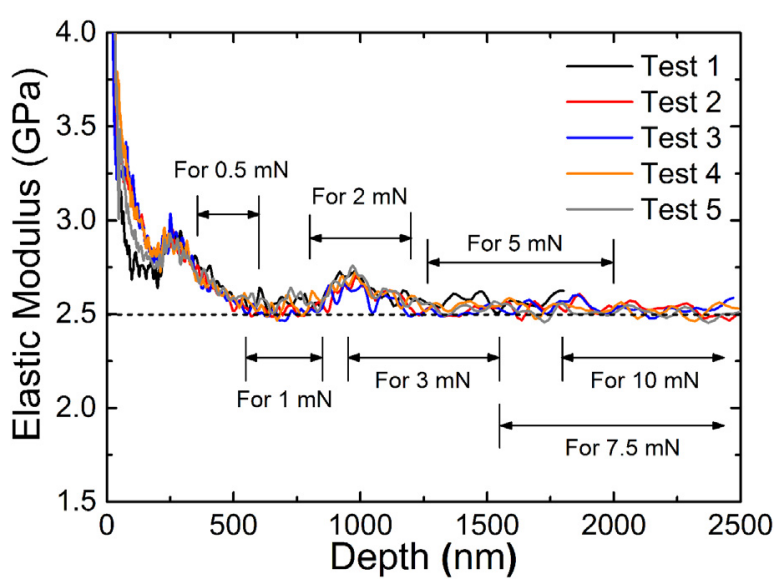

Fig. 7. Variation of elastic modulus with indentation depth measured by CSM, and the depth ranges during holding segment for indentation creep tests at seven different applied loads were also marked. creep tests at $2 \mathrm{mN}$ will be smaller than that determined at $1 \mathrm{mN}$ because the elastic modulus in the indentation depth range from $800 \mathrm{~nm}$ to $1200 \mathrm{~nm}$ is commonly larger than the elastic modulus from $550 \mathrm{~nm}$ to $850 \mathrm{~nm}$. The shear creep compliance determined by indentation creep tests at $5 \mathrm{mN}, 7.5 \mathrm{mN}$ and $10 \mathrm{mN}$ will coincide with each other because the elastic modulus is stable when the indentation depth is larger than $1200 \mathrm{~nm}$. The inference is exactly the same with the results shown in Fig. 6. This demonstrates that the nonlinear indentation creep behavior is caused by the non-uniform properties in the surface of the specimen rather than the nonlinear viscoelasticity.

A qualitative analysis could also support this viewpoint. For nonlinear viscoelastic materials, different applied stresses lead to nonlinear creep behavior. Since the stress distribution beneath the indenter is non-uniform in instrumented conical indentation, the creep behavior at points beneath the indenter is non-uniform. However, the indentation creep behavior is the synthesis of the nonuniform creep behavior at every point beneath the indenter. Also, the stress field beneath the indenter is similar as indentation depth increases because conical and pyramidal indenters are geometrically self-similar. This means the indentation creep behavior is independent of indentation depth (or applied load) if the material is homogeneous. In other words, conical indentation on nonlinear viscoelastic materials yields linear indentation creep behavior.

For nonlinear viscoelastic materials, since the indentation creep behavior is the synthesis of the non-uniform creep behavior at every point beneath the indenter, the shear creep compliance determined by indentation creep tests deviates from that determined by uniaxial tensile creep tests at a certain applied stress. Comparison of the shear creep compliance determined by indentation creep tests at applied load of $10 \mathrm{mN}$ and uniaxial tensile creep tests at applied stress of $15 \mathrm{MPa}$ is shown in Fig. 8. It is evident that the indentation results increase almost linearly and are much larger than the uniaxial tensile results.

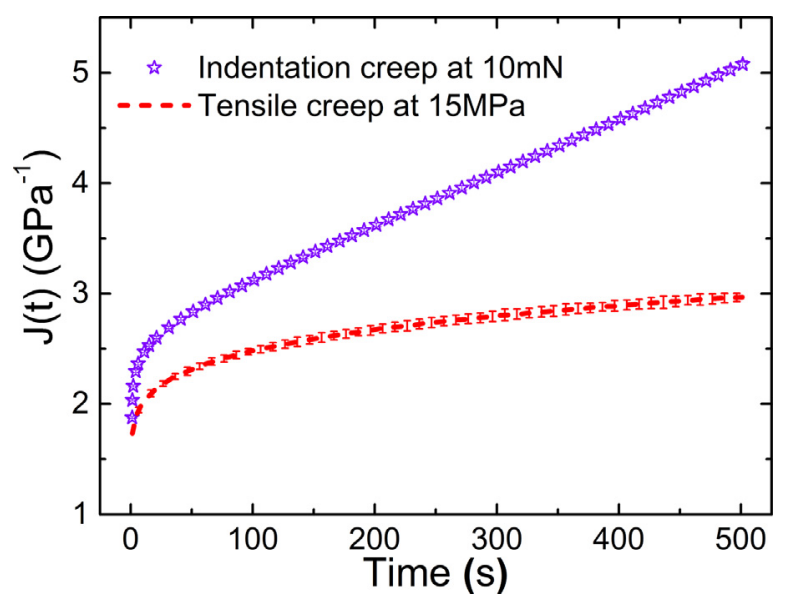

Fig. 8. Comparison of the shear creep compliance determined by indentation creep tests at applied load of $10 \mathrm{mN}$ and uniaxial tensile creep tests at applied stress of $15 \mathrm{MPa}$. 
The deviation could be interpreted with the aid of the PPmodel shown in Fig. 4. As discussed in subsection 4.1, the PP-model reduces to a Burgers model in series with one Voigt-Kevin unit (where the second locked Voigt-Kevin unit and the viscoplastic unit in PP-model do not work) for uniaxial tensile creep tests at $15 \mathrm{MPa}$. However, for conical indentation creep tests on PP, the locked VoigtKevin units are unlocked and the viscoplastic unit works in the plastic zone. Since the high stresses beneath the indenter tip can easily lead to material yielding and the plastic deformation is dominant, the indentation creep behavior is apt to be described by the full PP-model (a Burgers model in series with two Voigt-Kevin units and a viscoplastic unit). Clearly, the full PP-model yields larger creep compliance than the reduced PP-model does. As a consequence, the shear creep compliance determined by indentation creep tests is larger than that determined by uniaxial tensile creep tests.

\section{Conclusions}

PP used in the experiments was demonstrated to be nonlinear viscoelastic by uniaxial tensile creep tests at three different applied stresses. A novel phenomenological model consisting of springs, dashpots, stress-locks and sliders (see Fig. 2) was proposed to describe nonlinear viscoelasticity and stress-dependent shear creep compliance. In conical indentation creep tests on nonlinear viscoelastic PP, the nonlinear indentation creep behavior at shallow depth is caused by the non-uniform properties in the surface of the specimen rather than nonlinear viscoelasticity. In other words, the shear creep compliance of nonlinear viscoelastic PP determined by conical indentation tests at various applied loads will be the same if the specimen is homogeneous. Thus, indentation creep tests with a single conical indenter cannot be used to determine the stress-dependent shear creep compliance for nonlinear viscoelastic solids.

\section{Acknowledgements}

The authors would like to thank postgraduate student Y.J. Dai for specimen processing. The support from the National Natural Science Foundation of China (Grant Nos. $11402233,11025212,11272318,11372323$, and 11302231$)$ is gratefully acknowledged.

\section{References}

[1] H. Lu, B. Wang, J. Ma, G. Huang, H. Viswanathan, Measurement of creep compliance of solid polymers by nanoindentation, Mech. Time-Depend. Mat. 7 (2003) 189-207.

[2] M.L. Oyen, Spherical indentation creep following ramp loading, J. Mater. Res. 20 (2005) 2094-2100.

[3] R. Seltzer, Y. Mai, Depth sensing indentation of linear viscoelastic-plastic solids: a simple method to determine creep compliance, Eng. Fract. Mech. 75 (2008) 4852-4862.

[4] Y.T. Cheng, F.Q. Yang, Obtaining shear relaxation modulus and creep compliance of linear viscoelastic materials from instrumented indentation using axisymmetric indenters of power-law profiles, J. Mater. Res. 24 (2009) 3013-3017.

[5] A.S. Maxwell, M.A. Monclus, N.M. Jennett, G. Dean, Accelerated testing of creep in polymeric materials using nanoindentation, Polym. Test. 30 (2011) 366-371.

[6] J. Menčík, L.H. He, J. Němeček, Characterization of viscoelasticplastic properties of solid polymers by instrumented indentation, Polym. Test. 30 (2011) 101-109.

[7] G.J. Peng, T.H. Zhang, Y.H. Feng, R. Yang, Determination of shear creep compliance of linear viscoelastic solids by instrumented indentation when the contact area has a single maximum, J. Mater. Res. 27 (2012) 1565-1572.

[8] C.Y. Zhang, Y.W. Zhang, K.Y. Zeng, L. Shen, Characterization of mechanical properties of polymers by nanoindentation tests, Philos. Mag. 86 (2006) 4487-4506.

[9] C.A. Tweedie, K.J. Van Vliet, Contact creep compliance of viscoelastic materials via nanoindentation, J. Mater. Res. 21 (2006) 1576-1589.

[10] Y. Kucuk, C. Mollamahmutoglu, Y. Wang, H. Lu, Nonlinearly viscoelastic nanoindentation of PMMA under a spherical tip, Exp. Mech. 53 (2013) 731-742.

[11] B. Moginger, The determination of a general time creep compliance relation of linear viscoelastic materials under constant load and its extension to nonlinear viscoelastic behavior for the Burger model, Rheol. Acta 32 (1993) 370-379.

[12] E.H. Lee, J.R.M. Radok, The contact problem for viscoelastic bodies, J. Appl. Mech. 27 (1960) 438-444.

[13] S.C. Hunter, The hertz problem for a rigid spherical indenter and a viscoelastic half-space, J. Mech. Phys. Solids 8 (1960) 219-234.

[14] G.A.C. Graham, The contact problem in the linear theory of viscoelasticity, Int. J. Eng. Sci. 3 (1965) 27-46.

[15] T.C.T. Ting, Contact problems in linear theory of viscoelasticity, J. Appl. Mech. 35 (1968) 248-254.

[16] S. Jazouli, W. Luo, F. Brémand, T. Vu-Khanh, Nonlinear creep behavior of viscoelastic polycarbonate, J. Mater. Sci. 41 (2006) 531-536.

[17] M.L. Oyen, Indentation of Nonlinearly viscoelastic solids, Mater. Res. Soc. Symp. Proc. 1049 (2008).

[18] J. Menčík, L.H. He, M.V. Swain, Determination of viscoelastic-plastic material parameters of biomaterials by instrumented indentation, J. Mech. Behav. Biomed. 2 (2009) 318-325.

[19] ISO527-2:1993(E), Plastics - determination of tensile properties part 2: Test conditions for moulding and extrusion plastics.

[20] W.C. Oliver, G.M. Pharr, An improved technique for determining hardness and elastic modulus using load and displacement sensing indentation experiments, J. Mater. Res. 7 (1992) 1564-1583.

[21] G.J. Peng, T.H. Zhang, Y.H. Feng, Y. Huan, Determination of shear creep compliance of linear viscoelastic-plastic solids by instrumented indentation, Polym. Test. 31 (2012) 1038-1044. 